\title{
Mathematical correlation predicting stock tank oil density for Egyptian crude oils at standard conditions
}

\author{
A. N. El-Hoshoudy", S. E. M. Desouky, M. A. Betiha, S. Abdelraouf, M. Elaily \\ Department of Production, Egyptian Petroleum Research Institute, Naser City, Cairo, Egypt.
}

Email address:

azizchemist@yahoo.com(A. N. El-Hoshoudy)

\section{To cite this article:}

A. N. El-Hoshoudy, S. E. M. Desouky, M. A. Betiha, S. Abdelraouf, M. Elaily. Mathematical Correlation Predicting Stock Tank Oil Density for Egyptian Crude Oils at Standard Conditions. International Journal of Oil, Gas and Coal Engineering. Vol. 2, No. 4, 2014, pp. 55-58. doi: 10.11648/j.ogce.20140204.11

\begin{abstract}
Liquid density is one of the most important governing physical parameter of the fluid flow. Generally, oil density measured at standard conditions (14.65 psia and $\left.60^{\circ} \mathrm{F}\right)$ via Density Meter. Since there is a remarkable difference between calculated density from compositional analysis and measured one at standard conditions. So it is of great importance to use an accurate correlation to calculate the oil density at standard conditions. The proposed correlation correlates measured density with measured molecular weight, calculated molecular weight and calculated density which calculated from compositional analysis. Here, based on measured Egyptian oil reservoirs data; new correlation has been developed for prediction of oil density at standard conditions (14.65 psia and $\left.60{ }^{\circ} \mathrm{F}\right)$. Validity and accuracy of this correlation has been confirmed by comparing the obtained results of this correlation with experimental data for Egyptian oil samples. Checking the results of this correlation shows that the developed correlation results are in a high agreement with the experimental data.
\end{abstract}

Keywords: Oil Density, PVT Correlation, API Gravity, Compositional Analysis

\section{Introduction}

The crude oil density in general is defined as the mass of a given volume, and expressed in pounds per cubic foot or in $\left(\mathrm{kg} / \mathrm{m}^{3}\right)$. Oil density varies from $30 \mathrm{lb} / \mathrm{ft}^{3}$ for light volatile oil to $60 \mathrm{lb} / \mathrm{ft}^{3}$ for heavy crude oil with little or no gas solubility [1]. It is one of the most important oil properties, because its value substantially affects crude oil volume calculations. This vital oil property is measured in the laboratory as part of routine pressure, volume, temperature (PVT) tests [2]. In this study, the authors try to develop new correlation which predict stock tank oil density (i.e. free from solution gas) at standard conditions $(14.65$ psia and $60 \mathrm{~F})$ to treat a great problem for petroleum engineers and lab chemists concerned with the difference arise between the calculated density from compositional analysis and the measured one .One can resort to empirical PVT correlations to estimate the reservoir fluid data in the following cases: (1) inability to obtain a representative sample, (2) sample volume is insufficient to obtain a complete analysis, (3) collected sample is non representative, (4) quality check lab analysis, (5) lab analyses are in error, (6) estimating the potential reserves to be found in an exploration prospects, and (7) evaluating the original oil in place and reserve for a newly discovered area before obtaining the laboratory analysis to justify a primary development plan[3]. All correlations were concerned with crudes from different locations and presumably of different characteristics. Each study claimed that the resulting correlation would provide the best approximation of PVT properties for the local region compared to the other commonly used correlations. Studies performed by El-hoshoudy et al[4] ,Macary and Batanony [5],Hanafy et al[6], Glasso[7] ,Dokla and Osman[8] ,Marhoun[2], Labedi[9] all supported this conclusion[5]. Multiple linear/nonlinear least-squares regression analysis will be used to develop the new correlations after screening of the used parameters. In addition, accuracy of developed correlations determined by comparing the obtained results with the experimental ones through statistical error means $\left(\mathrm{E}_{\mathrm{r}}, \mathrm{E}_{\mathrm{a}}, \mathrm{E}_{\max }, \mathrm{E}_{\min }, \mathrm{S}\right.$ and $\mathrm{r}$ ) and graphical error means (cross plot analysis). Furthermore, the new correlations will be validated using other experimental data sets not used in the correlations development [10]. 


\section{Experimental Data}

In this study, PVT measured data of five hundreds and forty two (542) samples from Egyptian oil reservoirs had been used. These data include measured oil density at standard conditions (14.65 psia and $\left.60^{\circ} \mathrm{F}\right)$, measured molecular weight, calculated molecular weight and calculated density from compositional analysis. All these samples were measured in the PVT lab at Egyptian petroleum research institute. A brief description of the utilized instruments is given below.

\subsection{Density Meter (DMA 4100)}

Measurements of oil density at standard conditions (14.65 psia and $60{ }^{\circ} \mathrm{F}$ ) are carried out by Density Meter (Anton paar GmbH, Graz, Austria), which also may be used for measurements at moderately high pressures and high temperatures up to $\left(150 \mathrm{psi}\right.$ and $\left.194{ }^{\circ} \mathrm{F}\right)$.

\subsection{Molecular Weight (CRYTTE WR ${ }^{T M}$ )}

Most of the early molecular weight determinations on hydrocarbon oils used simple forms of the cryoscopic (freezing point depression) method [11]. In this technique the freezing point of a mixture of benzene and the oil's heavy ends is measured and compared to the freezing point of pure benzene. This allows a determination of the heavy fraction's molecular weight and density. Also, molecular weight apparatus (Ruska, Model No.5009F, Precision system Inc, USA 1994) is used for heat exchange evaluations of distillation columns and for monitoring the progress of cracking processes.

\subsection{Gas Liquid Chromatography}

The stock tank oil composition is determined, invariably, by gas chromatography (GC; CLARUS 500 GC, Perkin Elmer Inc, USA 2002- TotalChrom Version 6.3 Software). Basic characteristics of Egyptian crude oils data considered here are given in table 1.

Table 1. Data ranges of Egyptian crude oils.

\begin{tabular}{llll}
\hline Properties & Min & Max & Average \\
\hline API & 32.12 & 68.59 & 48.55 \\
Molecular Weight & 108.35 & 176.66 & 144.82 \\
\hline
\end{tabular}

\section{Development of the Proposed Correlations}

Proposed correlation based on real data, which almost covers Egyptian oil types. This correlation represents oil density at standard conditions as a function of calculated density, apparent molecular weight from compositional analysis and measured molecular weight. Standing and Katz [12] proposed a procedure for calculating crude oil density from compositional analysis.
Firstly, total weights of $1 \mathrm{lb}$-mole of the mixture, lb/lbmole is calculated by the following relation

$$
m_{t}=\sum x_{i} M_{i}
$$

Secondly, calculated density of hydrocarbon liquid mixtures is calculated by the following relation.

$$
\rho_{c}=\frac{\sum_{i}^{n} x_{i} M_{i}}{\sum_{i}^{n} \frac{x_{i} M_{i}}{\rho_{i}}}
$$

In this study the authors proposed that measured density is a strong function of measured molecular weight, calculated molecular weight and calculated density, where the term $\left(\mathrm{MW}_{\mathrm{c}}\right)$ used as an alternative symbol for $\left(\mathrm{m}_{\mathrm{t}}\right)$.

$$
\rho_{m}=f\left(\rho_{c}, M W_{m}, M W_{c}\right)
$$

Multiple least-square non linear regression analysis was utilized to develop this new density correlation. The fundamental concept of regression analysis is to fit a function of independent variables to a given set of data points in order to estimate or predict one dependent variable as accurately as possible. The nonlinear procedure requires a model expression, parameter names, initial guess values of parameters, and derivatives of the model with respect to each parameter. Developed correlation in this study is as follow:

\subsection{Correlation of Stock Tank Oil Density at Standard Conditions.}

The best model that fits the five hundred and forty two experimental density data was found to be

$$
\left(\rho_{\mathrm{m}}\right)=\mathrm{e}^{\mathrm{A} *}\left(\rho_{\mathrm{c}}\right)^{\mathrm{B} *}\left(\mathrm{MW}_{\mathrm{m}} / \mathrm{MW}_{\mathrm{c}}\right)^{\mathrm{C}}
$$

This nonlinear model was linearized by applying logarithmic transformation which formed the following final linear empirical correlation:

$$
\mathrm{LN}\left(\rho_{\mathrm{m}}\right)=\mathrm{A}+\mathrm{B} * \mathrm{LN}\left(\rho_{\mathrm{c}}\right)+\mathrm{C} * \mathrm{LN}\left(\mathrm{MW}_{\mathrm{m}} / \mathrm{MW}_{\mathrm{c}}\right)
$$

Where;

$$
\mathrm{A}=0.177 \quad \mathrm{~B}=1.529 \quad \mathrm{C}=0.002
$$

\section{Results and Discussion}

\subsection{Evaluation Procedure.}

Statistical and graphical error analyses are the criteria adopted for the evaluation in this study [2]. The developed PVT correlation is applied to the Egyptian crude oil data set and a comprehensive error analysis is performed based on a comparison of the predicted value with the original experimental value. 


\subsubsection{Statistical Error Analysis.}

Table 2 lists six statistical error parameters that are used in this study to evaluate the developed correlation data in comparison with the experimental data. It's found from statistical means that the new developed correlation has a great repeatability and accuracy.

Table 2. Statistical accuracy of standard density correlation for the data used in model development.

\begin{tabular}{lllllll}
\hline $\begin{array}{l}\text { Statistical } \\
\text { Parameter }\end{array}$ & $\mathbf{E}_{\mathbf{r}}$ & $\mathbf{E}_{\mathbf{a}}$ & $\mathbf{E}_{\mathbf{m a x}}$ & $\mathbf{E}_{\min }$ & $\mathbf{S}$ & $\mathbf{r}$ \\
\hline This study & 0.1902 & 0.7299 & 4.3296 & 0.0013 & 0.9471 & 0.9623 \\
\hline
\end{tabular}

\subsubsection{Graphical Error Analysis.}

Graphical means help in visualizing the accuracy of a correlation. Cross plot graphical analysis technique was considered in this study for comparative evaluation. The cross plots of estimated values versus experimental values are shown in Figures 1 and 2.

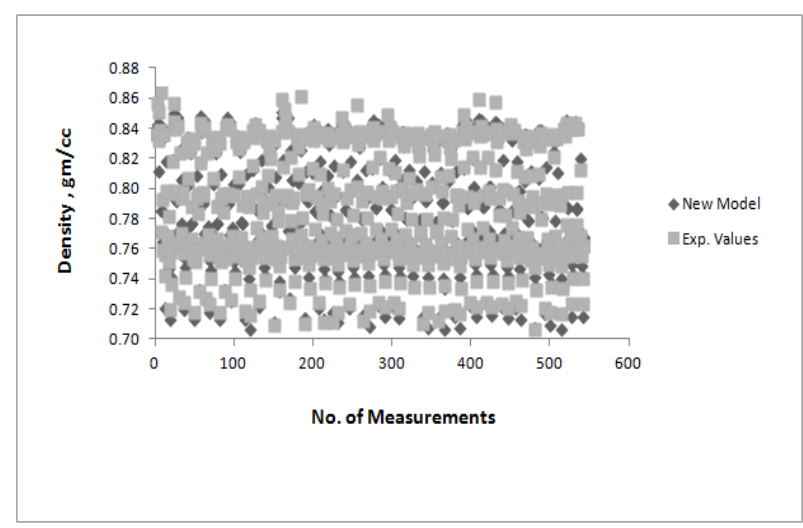

Fig.1. Cross plot of New Model and Experimental Values.

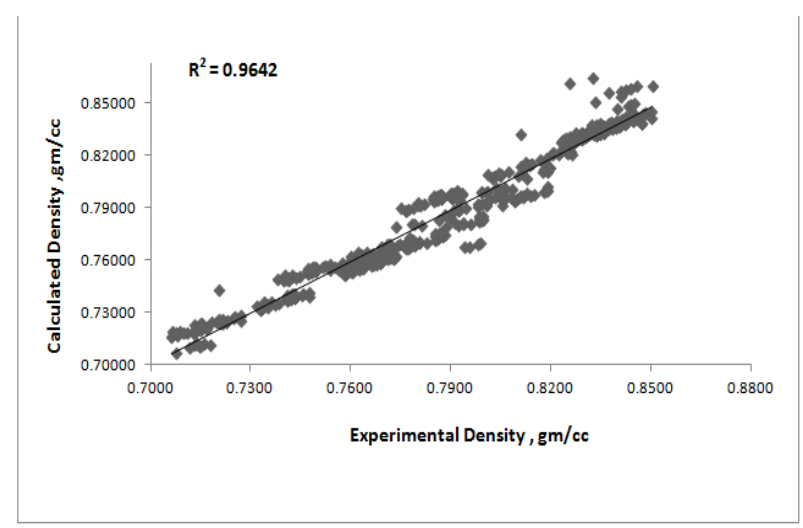

Fig.2. New Model for Stock Tank Oil Density at Standard Conditions.

\subsection{Validation of the New Correlations}

In order to examine the applicability and reliability of the newly developed empirical correlation, it was validated using seventeen (17) data sets that were not used in the development of the newly correlation.

Table 3 summarizes the results of error analysis of the newly developed correlation. The errors in the existing correlation using the new data sets are considered very close to the errors resulted from the data sets used to develop the new correlations.

Table 3. Statistical accuracy of standard density correlation for the data used in model validation.

\begin{tabular}{lllllll}
\hline $\begin{array}{l}\text { Statistical } \\
\text { Parameter }\end{array}$ & $\mathbf{E}_{\mathbf{r}}$ & $\mathbf{E}_{\mathbf{a}}$ & $\mathbf{E}_{\max }$ & $\mathbf{E}_{\min }$ & $\mathbf{S}$ & $\mathbf{r}$ \\
\hline This study & 0.1562 & 0.6998 & 4.025 & 0.0912 & 0.9665 & 0.9710 \\
\hline
\end{tabular}

\section{Conclusion}

Based on the above results, the following conclusions can be drawn:

1. A new correlation estimating stock tank oil density at standard conditions for Egyptian oils has been proposed based on real data of the different Egyptian oil types.

2. The new correlation overcome the differences arises between measured density and calculated one from compositional analysis .

3. In comparison with experimental data, new correlation has a better accuracy and performance for predicting the density of Egyptian oils at standard conditions $\left(14.65 \mathrm{psia}\right.$ and $\left.60^{\circ} \mathrm{F}\right)$.

4. It should be mentioned that, the proposed correlation considered more relevant and applicable to Egyptian oil reservoirs so, application of this correlation for other geological regions should be checked.

\section{Nomenclature}

API stock tank oil API gravity@60 $\mathrm{F}$

$M_{i}=\quad$ molecular weight of component i, gmol ${ }^{-1}$

$\rho_{\mathrm{m}} \quad$ measured density, $\mathrm{gm} / \mathrm{cc}$

$\rho_{\mathrm{c}} \quad$ calculated density, $\mathrm{gm} / \mathrm{cc}$

$E_{\mathrm{r}} \quad$ average percent relative error

$E_{a} \quad$ average absolute percent relative error

$\mathrm{E}_{\min } \quad$ minimum absolute percent relative error

$\mathrm{E}_{\max .} \quad$ maximum relative error absolute percent

$X_{i}=\quad$ mole fraction of component $\mathrm{i}$ in mixture.

$M_{t}=\quad$ molecular weight of $1 \mathrm{~g}$-mole of mixture, $\mathrm{g} / \mathrm{g}$-mole.

$\rho_{\mathrm{i}}=\quad$ density of pure component $\mathrm{i}$ at standard conditions, $\mathrm{g} / \mathrm{cc}$

$\mathrm{MW}_{\mathrm{m}}$ measured molecular weight

$\mathrm{MW}_{\mathrm{c}}$ calculated molecular weight

S standard deviation

r correlation coefficient 


\section{References}

[1] Beggs, H. D. and Robinson J. R. "Estimating the viscosity of crude oil systems". JPT. 1975; 9: 1140- 1141.

[2] Al-Marhoun, M. A. "PVT correlations for Middle East crude oils". J. Pet. Technol. $1988 ; 40$ (5) : 650 - 666.

[3] Hanafy, H.H., Macary S.M., ElNady Y.M., Bayomi A.A. and El-Batanoney M.H. "A New Approach for Predicting the Crude Oil Properties." SPE 37439. 9-11 March 1997; presented at the SPE production operation symposium held in Oklahoma City, Oklahoma.

[4] El-hoshoudy,A. N., Farag A.B., Ali O.I.M., El-Batanoney M. H., Desouky S.E.M. and Ramzi M. "New Correlations for Prediction of Viscosity and Density of Egyptian Oil Reservoirs." Fuel May 2013; 112:277-282.

[5] Macary,S.M. and El-Batanoney M.H. "Derivation of PVT Correlations for the Gulf of Suez Crude Oils." EGPC $11^{\text {th }}$ Petroleum Exploration and Production Conference, 1992.

[6] Hanafy, H.H., Macary S.M., ElNady Y.M., Bayomi A.A. and
El-Batanoney M.H. "Empirical PVT Correlations Applied to Egyptian Crude Oils Exemplify Significance of Using Regional Correlations." SPE 37295, 18-21 February 1997; presented at the SPE international symposium on oil field chemistry held in Houston, Texas.

[7] Glaso, O. "Generalized pressure-volume-temperature correlation for crude oil system”. JPT. 1980; 2: 785- 795.

[8] Dokla, M.E. and Osman M.E. "Correlations of PVT Properties for the UAE Crudes," SPE Formation Evaluation, March 1992; 7: 41-46.

[9] Labedi, R., "Improved correlations for predicting the viscosity of light crudes". J.Pet.Sci. Eng. 1992; 8: 221- 234.

[10] Younger, M.S."Handbook for Linear Regression". USA.Wadsworth, Inc., Belmont 1999.

[11] ASTM D2224-78 "Method of Test for Mean Molecular Weight of Mineral Insulating Oils by the Cryoscopic Method". 1983.

[12] Standing M. B. and Katz D. L. "Density of Natural Gases". Transactions of the AIME, 1942; 146:140:149. 